faithful to his own interpretations. Unlike the Calanoida, in which many of the life-histories are complete, the Harpacticoida are little known and until the publication of this volume in no case had the sequence of the copepodid stages been fully worked out. Differences in the nauplian stages are very small and in the copepodid stages measurements are unreliable owing to the contractility of the body. The general characters of the Harpacticid nauplius are given in the first volume. In the second the nauplii of Canthocamptus pygmoeus are described as typical and the copepodid stages of Canthocamptus staphylinus, which are precisely comparable to those of a calanoid. The nauplii of other species are described and figured whenever possible.

The distribution of the Harpacticoida offers many interesting problems and there is much work to be done in clearing these up. The author's discussions under the head of bionomics of the separate species are very valuable and in some cases at least tend to repudiate the idea of any influence due to the glacial period.

The descriptions of the separate species as found in Great Britain are full and clear, involving much laborious counting and figuring of spines and setæ, the figures as before being models of what such illustrations should be.

Marine as well as freshwater copepod workers will be greatly helped by this important work and will look forward to the third volume.

\section{The Science of Colloids}

Kapillarchemie: eine Darstellung der Chemie der Kolloide und verwandter Gebiete. Von Prof. Dr. Herbert Freundlich. Band 2. Vierte unter Mitwirkung von J. Bikerman umgearbeitete Auflage. Pp. xi + 955. (Leipzig: Akademische Verlagsgesellschaft m.b.H., 1932.) 69 gold marks.

DROGRESS in science, like corrosion, is apt to travel along interfaces, and few areas recently brought under the plough of adventurous workers have yielded a richer harvest than the territory between chemistry and physics occupied by the science of colloids. All the tools available in both the classical branches of knowledge are necessary for the exploitation of this field, yet it requires also its own distinctive outlook and skill. The growth of standard works in a new subject such as this is naturally slow, for each worker

No. 3293, Vol. 130] tends to review the field from a point of view dependent on his special explorations, and in consequence many of the earlier books were partial in their account of the work done and it was difficult to obtain from them a clear and balanced view of the whole subject.

Prof. Freundlich's "Kapillarchemie" has always been largely free from this defect, and with almost uncanny foresight he adopted in the first edition in 1909 the classification which has served for each succeeding edition. The first volume of the present edition, published two years ago, contains the introductory matter on which the subsequent development of the theme depends, and this second volume will appeal more to the colloid chemist who is interested in the practical side of the subject. In it the typical colloid systemssols and gels-are systematically discussed, and it is very significant that a much larger proportion of generalised statement is now possible, at least for sols, than could be made a few years ago ; so that only one-sixth of the total space devoted to lyophobe sols is now required for individual properties, whereas formerly it was necessary to deal with almost every sol singly. The gels and to some extent the lyophile sols are too distinctive in many properties for general treatment.

One of the most interesting recent developments in the study of colloids is the application of X-ray analysis to the constituent particles of sols and to such gels as rubber and cellulose and their derivatives. The research which has been carried out in these directions is ably summarised and illustrated. The same may be said of other modern work ; it is, indeed, very satisfactory to find even some of the more obscure memoirs discussed systematically and in proportion.

While the output of work along the main lines continues in ever-increasing volume, there is evidence that some of the less obvious though not less important systems are being studied. Sols and gels in non-aqueous media, in which ionic effects are absent or profoundly modified, smokes, fogs, foams and colloid systems in solid media, all deserve further attention, if only because of their industrial importance. The meagre information available is indicated in this work.

It is perhaps superfluous to add that in style and completeness, this new edition of "Freundlich" easily maintains its place as the foremost textbook of colloid chemistry.

P. C. L. Thorne. 